\title{
Correction to: Community Low-Dose CT Lung Cancer Screening: A Prospective Cohort Study
}

\author{
Vincent K. Lam ${ }^{1} \cdot$ Mary Miller $^{2} \cdot$ Lynn Dowling $^{2} \cdot$ Shyamali Singhal ${ }^{2} \cdot$ Robert P. Young $^{3} \cdot$ Elwyn C. Cabebe $^{4}$
}

Published online: 24 September 2019

○) Springer Science+Business Media, LLC, part of Springer Nature 2019

Correction to: Lung (2015) 193:135-139

https://doi.org/10.1007/s00408-014-9671-9

The original version of this article contained an error in the usage of the term "false positive rate". The intention of the authors in those instances was simply to compare the absolute percentage of false positive results in the study vs the NLST, not to make any observations about false positive rate in the strict statistical sense (i.e. Type I error probability).

Publisher's Note Springer Nature remains neutral with regard to jurisdictional claims in published maps and institutional affiliations.

The original article can be found online at https://doi.org/10.1007/ s00408-014-9671-9.

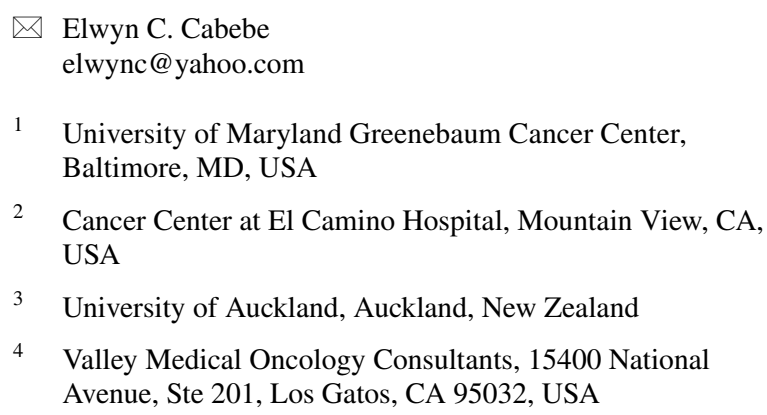

4 Valley Medical Oncology Consultants, 15400 National Avenue, Ste 201, Los Gatos, CA 95032, USA 